\title{
Turismo, patrimonio y lugar en una aldea alemana del Volga.
} Reflexiones a partir de la colonia Santa Anita (Argentina)*

\section{Turismo, Patrimonio y Lugar en Aldea Alemana del Volga. Reflections from Colonia}

Santa Anita [Argentina]

Fabián Claudio Flores ${ }^{1}$

Darío Windholz ${ }^{2}$

* Recebido em: 03.04 .2020 Aprovado em: 12.06.2020.

1 (CONICET, GIEPEC-Universidad Nacional de Luján, Argentina) Email: licfcflores@ hotmail.com.

2 (GIEPEC-Universidad Nacional de Luján, Argentina) $\quad-$ Email: dariow1991@ hotmail.com.
Resumen: La Colonia de Santa Anita se encuentra ubicada en la provincia de Entre Ríos, a $360 \mathrm{~km}$. de la Capital Federal de Argentina y $220 \mathrm{~km}$. de Paraná (capital de la provincia). La historia territorial de esta localidad está íntimamente vinculada a la inmigración de alemanes del Volga que fundaron la colonia agrícola hacia 1901. En la actualidad, a las clásicas e históricas actividades agrícolas se está sumando el turismo como una actividad en crecimiento a partir de la puesta en valor de atractivos naturales y culturales. En este sentido, el artículo se propone indagar los vínculos entre turismo, patrimonio y lugar en torno a esta localidad rural de la provincia de Entre Ríos (Argentina) poniendo sobre la mesa la discusión geográfica al respecto de las prácticas turísticas del (y en él) lugar. Metodológicamente la pesquisa combinó el trabajo de campo, las entrevistas a actores claves, el análisis de material visual de promoción turística y la bibliografía específica.

Palabras claves: turismo cultural; patrimonio; lugar; colonias agrícolas; inmigración.
Abstract: The Colony of Santa Anita is located in the Entre Rios province, $360 \mathrm{~km}$ away from Argentina's Capital Federal and 220 $\mathrm{km}$. away from Paraná (the province capital). The territorial history of this location is deeply linked to the Volga Germans immigrants, who founded this agrarian colony by 1901 . Nowadays, besides the classic and historical farming activities, tourism is a new activity that has been rising making a good use of the cultural and natural attractions. In this sense, this article puts forth to investigate the link between tourism, legacy and the land around this agrarian location in the province of Entre Rios (Argentina), bringing in the geographical discussion about the touristic practices of and into this place. Methodologically, the research mixed fieldwork, interviews with key stakeholders, the analysis of visual material for tourism promotion and the specific bibliography.

Keywords: culture tourism, heritage, place, agrarian colonies, immigration. 


\section{Fabián Claudio Flores}

\section{Darío Windholz}

${ }^{3}$ La colonia de Santa Anita es una aldea rural que se encuentra situada en la provincia argentina de Entre Ríos y pertenece administrativamente Departamento llamado "Uruguay".

\section{1 - Introducción}

Tanto el patrimonio como el turismo son dos categorías que están estrechamente vinculadas y que poseen la particularidad de poder ser indagadas en clave espacial. Sin embargo, muchos de los estudios que pretenden evaluarlas caen en algunos vicios que le quitan la complejidad y terminan reduciéndolas a miradas que reifican su contenido social, histórico y procesual, perdiendo la riqueza que implica un análisis geográfico del problema.

Lejos de estas lógicas, el presente artículo se propone indagar los vínculos entre turismo, patrimonio y lugar en torno a la localidad rural de Santa Anita ${ }^{3}$. El "pasado" de esta colonia migratoria vinculada a los alemanes del Volga, su paisaje rural material e inmaterialmente presente, y las particularidades de una identidad territorial que se inventa y reinventa a partir de ese "pasado" constituyen elementos centrales para poner sobre la mesa la discusión geográfica sobre las prácticas turísticas del (y en el) lugar.

El trabajo se ordena en torno a cuatro partes: en el primer apartado ponemos en discusión algunas de las categorías nodales que articulan el trabajo: turismo, patrimonio, lugar, y la modalidad del turismo cultural, así como también algunas consideraciones de orden metodológico que exponen los criterios y estrategias que se utilizaron. En una segunda instancia rastreamos el pasado y presente de la colonia San Anita advirtiendo los hechos, procesos, actores y discursos que circulan y circularon en la localidad; luego, en una tercera parte clave, centramos la mirada en los procesos de patrimonialización y turistificación del lugar, evaluando las realidades y potencialidades de ambos procesos. Finalmente, en las conclusiones volvemos con algunos de los planteos iniciales, deslizamos algunas ideas síntesis e interrogantes para futuras pesquisas.

\section{2 - Discusiones teóricas y metodológicas}

Este artículo se propone analizar el proceso de construcción de lugares en torno a una localidad entrerriana: la colonia de Santa Anita, partiendo de un acercamiento al lugar desde la fenomenología en donde se pone el énfasis en las relaciones sociales, las prácticas, los discursos espaciales y las representaciones que se hallan involucrados en la construcción de lugares particulares (CRESSWELL, 2007: 51).

En este sentido, entendemos al turismo "como un proceso y una práctica social, económica y cultural en la que se involucran diversos actores -residentes, políticos, agencias, empresarios- para la construcción y promoción de destinos y atractivos turísticos" (PÉREZ WINTER, 2017: 263). Esta práctica tiene fuertes implicancias de orden espacial que dan cuenta de la necesidad de aplicar un abordaje geográfico complejo y que ponga la mirada en el 


\section{Fabián Claudio Flores}

\section{Darío Windholz}

".

4 "Lo que sostengo [...] es que hay más bien un discurso hegemónico sobre el patrimonio, que actúa para constituir la forma en que pensamos, hablamos y escribimos sobre el patrimonio. Por lo tanto, el discurso del patrimonio naturaliza la práctica de reunir a los sospechosos habituales para conservar y 'transmitir' a las generaciones futuras, $y$ al hacerlo promueve un cierto conjunto de valores culturales de la élite occidental como universalmente aplicables. En consecuencia, este discurso valida un conjunto de prácticas y actuaciones, que pueblan tanto las construcciones populares como las de expertos de 'patrimonio' y socava las ideas alternativas y subalternas sobre el 'patrimonio'. Al mismo tiempo, el 'trabajo' que el 'patrimonio' 'hace' como práctica social y cultural queda oculto, como resultado de los efectos naturalizadores de lo que yo llamo el 'discurso del patrimonio autorizado" (SMITH, 2006: 2). conjunto de singularidades, tensiones y negociaciones que operan en dichos procesos.

Dos categorías nodales articulan nuestra lectura sobre el lugar: por un lado, el turismo como práctica espacial, y por el otro lado el patrimonio como potencial activador de dicha actividad. Es por eso que nos parece central -en esta primera instancia- dejar sentadas las bases de las formas en las que conceptualizamos y vinculamos ambas categorías analíticas en torno a la construcción del lugar.

En primer término vale aclarar que -muy por el contrario- el turismo no es una práctica nueva; pero sí se trata de una actividad muy dinámica que va generando nuevas posibilidades, respondiendo a nuevas demandas, nichos y lugares. Por eso es clave poner la atención en la puesta en valor de los atractivos y la turistificación de los lugares considerando que son -ante todo- resultado de un proceso social, político, histórico y cultural (ALMIRÓN, 2004; BERTONCELLO, 2002; BERTONCELLO, CASTRO y ZUSMAN 2003). Así, sitios y localidades que en determinados momentos (y contextos) no eran considerados lugares turísticos pueden activar lógicas novedosas que pongan en valor determinados bienes naturales o patrimoniales como atractivos turísticos. Entonces, los atractivos son resultado de un complejo proceso de selección donde "ciertos rasgos o atributos de los lugares se convierten en atractivos turísticos a través de una asignación social” (BERTONCELLO,
2008: 7). Una vez que se mitigan las disputas y que se seleccionan algunos rasgos, se habilita el proceso de legitimación del atractivo y las posibles transformaciones territoriales para conformar al lugar en tanto destino turístico (FLORES, CÁCERES, 2019). Por eso los atractivos son siempre resultado de una invención, y por ello es importe hurgar en las formas y las tensiones que se generan en el marco de estos procesos.

En segundo término, el patrimonio aparece como una categoría polisémica y controversial que tiene siempre fuertes implicancias espaciales. De manera provocadora Laurajene Smith (2011), siguiendo a Bendix, menciona que "el patrimonio no existe" (2009: 255) ${ }^{4}$; al menos al referirse a las miradas que suelen cosificar al patrimonio como ese legado que proviene del pasado y se proyecta en el futuro de las sociedades. Lejos de estas miradas, y retomando la perspectiva de Smith entendemos al patrimonio "como un proceso cultural que tiene que ver con la negociación de la memoria, la identidad y el sentido de lugar. Es un proceso activo de recordar, olvidar y conmemorar que se implementa para ayudar a navegar y mediar el cambio cultural y social, así como temas sociales y políticos contemporáneos." (SMITH, 2011: 42). Y además, "esta elección sociocultural implica que el elemento tomado como patrimonio cultural será teóricamente conservado y protegido, en tanto que será valorado por un significado que traspasa su función material, su cosificación, siendo entonces asumido como algo 
5 "El turismo cultural puede ser un positivo instrumento de desarrollo local y regional, entendido esto último desde una visión socioeconómica que permita una equitativa distribución de los beneficios, ya sean de carácter económico, social y cultural en las comunidades anfitrionas" (TOSELLI, 2006: 177).

6 Este tiene la particularidad de conservar el patrimonio material de los "antepasados" y "pioneros". Poseen un archivo con documentación de acceso libre y gratuito con materiales audiovisuales que incluye programas específicos con contenido "volguense" que mantienen relatos, historias de vida e historias de la comunidad. Los avances tecnológicos permiten que por medio de internet acceder a otros recursos como la radio local o los periódicos de la comarca, todos tenidos en cuenta en esta investigación. propio" (SANTANA TALAVERA, 2002:8). Esta particularidad no es un dato menor ya que a la hora de la puesta en valor del patrimonio y su potencial turistificación todos estos aspectos son centrales para considerar.

Así, patrimonio y turismo aparecen estrechamente ligados en la medida en que objetos o atributos que son percibidos como bienes valorados por una sociedad (en torno a un discurso hegemónico) son preservados y, al mismo tiempo, mercantilizados y puestos en valor como atractivos turísticos; el patrimonio -entonces- termina siendo producido como una mercancía más, en función de una demanda efectiva de un turismo presente o potencialmente futuro. Este salto del patrimonio al turismo, por un lado, suele estar mediado por procesos políticos, sociales, económicos y culturales; procesos complejos en los que participan una gama de actores muy diversa con desigual poder de decisión y acción en la patrimonialización y turistificación de los lugares; y por otro lado, son escoltados por discursos hegemónicos que los legitiman y que se construye desde los sectores de poder (SMITH, 2006; PÉREZ WINTER, 2015) Poner el foco en ese entramado es central para complejizar una lectura desde la geografía cultural, tanto de las prácticas turísticas como de la patrimonialización y la construcción de lugares turísticos.

Dentro del amplio universo de modalidades turísticas, el turismo cultural (también denominado turismo de patrimonio o turismo patrimonial) subyace como una alternativa cada vez más presente en muchos sitios del mundo. Esto se vincula con varios factores como la demanda creciente de "nuevos" turistas, la puesta en valor de las imágenes de lugares y paisajes que circulan constantemente, el interés creciente por consumir el patrimonio hasta la valorización positiva de la cultura y la proliferación de modelos turísticos entendidos como salida económica en aquellos ámbitos donde no se cuenta con una actividad consolidada. ${ }^{5}$

En síntesis, nos parece fundamental centrarnos en el cruce entre turismo, patrimonio y lugar como un valioso esquema para poder pensar las prácticas relacionadas al turismo en una localidad donde el entorno natural, el pasado migratorio, las identidades territoriales y las tensiones del presente habilitan una lectura cultural del fenómeno.

Metodológicamente, este artículo se ordena a partir de la casuística situada en torno a una localidad entrerriana de la Argentina, y mediante un abordaje integral desde la geografía cultural y el constructivismo geográfico. Varias son las herramientas cualitativas que se utilizaron para la búsqueda, procesamiento y evaluación de los datos: a) se realizaron entrevistas a diferentes actores involucrados en los procesos que se están explorando; b) se analizaron reglamentaciones y normativas que operan en la regulación de dichos fenómenos; c) se trabajó con el análisis e interpretación de dispositivos visuales (folletería, páginas web, redes sociales, blog, páginas de oferta turística y de viajes, etcétera); d) uso 


\section{Darío Windholz}

y análisis de materiales cartográficos digitales y e) la búsqueda de información en sitios claves de la localidad como el museo local y la casa del fundador, especializados en herramientas, arquitectura y otros bienes donde se guardan libros, periódicos y documentos de la colonia. ${ }^{6}$

\section{3 - La Colonia: pasado y presente}

Santa Anita fue fundada el 14 de Julio de 1900 por el Padre Enrique Becher junto a otros colonos alemanes del Volga pertenecientes a la Sociedad del Verbo Divino, quienes realizaron la compra, sin contar con fondos, de un campo denominado "Santa Anita" ubicado en la provincia de Entre Ríos, a 360 km. de la Capital Federal y 220 km. de Paraná (capital de la provincia) (Figura 1). Enteradas de dicha adquisición, muchas familias oriundas de Rusia que se habían asentado en Crespo, Valle María, Aldea Brasilera, Santa María, San Rafael, Cerrito, Spatzenkutter, María Luisa y Lucas González, e incluso en la provincia de Córdoba (como el caso de la familia Kippes) encontraron la solución al problema de la escasez de tierras para explotar y se instalaron en el nuevo territorio fundado. Así, para 1901 eran 60 las familias que provenían de las aldeas de la costa del Paraná y que conformaron la Colonia llamada "Santa Anita".

Figura 1. Localización de la Colonia de Santa Anita (Entre Ríos, Argentina).
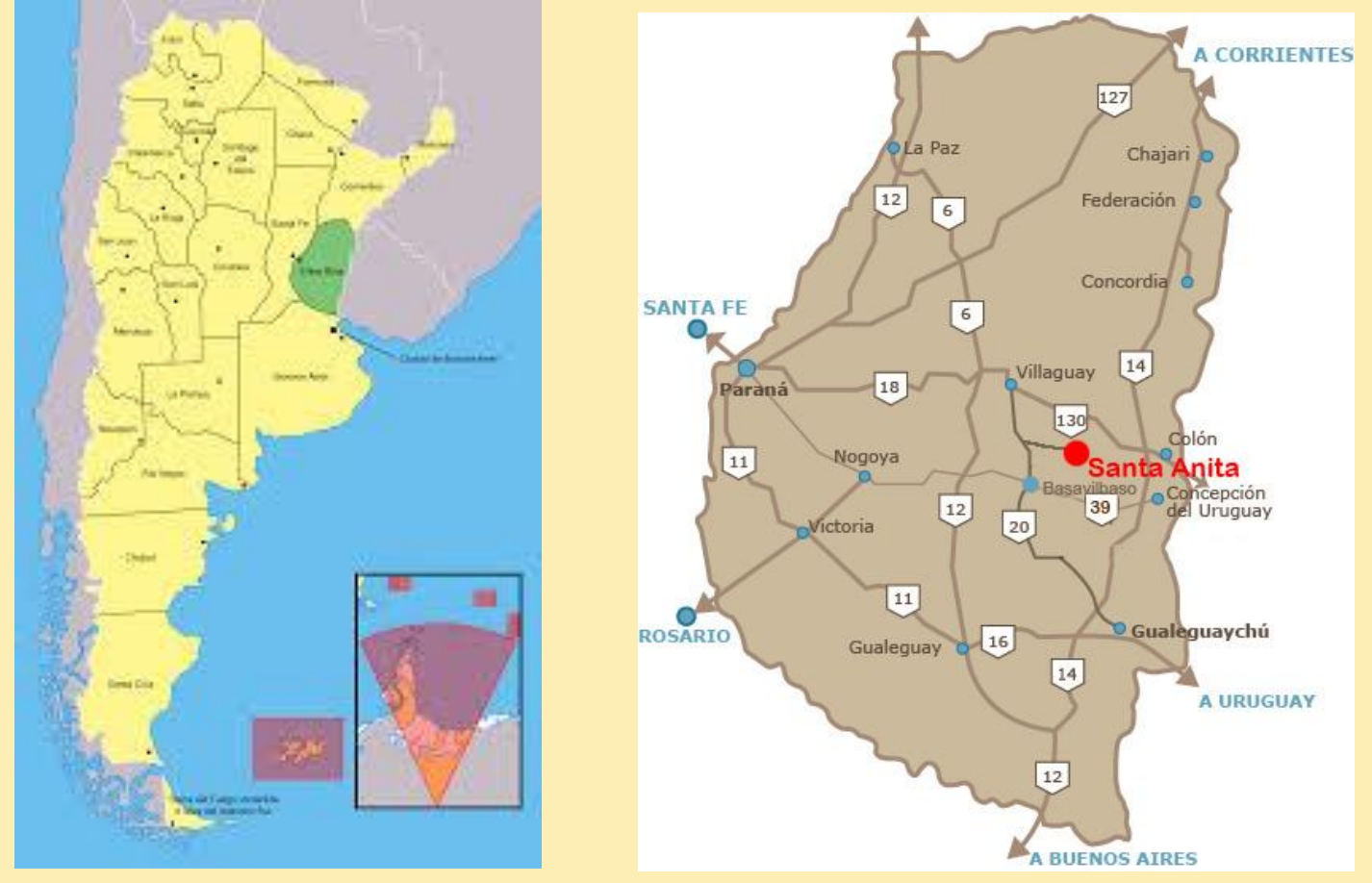

Fuente: Ecured https://www.santaanita. gob.arl (última consulta: agosto de 2020)

Dossiê Turismo: entrecruzamentos de cultura, memória e desenvolvimento 
Para la distribución de tierras (ver figura 2), los alemanes del Volga se basaban en pautas culturales que le otorgaban ciertas características a la organización del espacio y que resultaban exóticas para las autoridades de la época. En Santa Anita, el Padre Becher organizó la venta de las parcelas de tal manera que seguía siendo el propietario de la tierra hasta que los colonos cancelasen el valor de su respectiva parcela en suma a la maquinaria y demás prestaciones. Es decir, con la toma de posesión de la parcela cualquier colono ya era considerado propietario, sin embargo, recién después del pago total de la deuda se le otorgaba la escritura de propiedad. De acuerdo a la composición de la familia, los colonos recibían terrenos de distintas dimensiones: las más grandes parcelas de 200 hectáreas, mientras que las menos numerosas recibían 50 hectáreas y debían aportar un canon por cada unidad adquirida destinada a la construcción del templo. Además, tenían la ventaja de seleccionar el lote libremente con el fin de que "las familias procedentes de un mismo pueblo puedan agruparse" (HONEKER y JACOB, 2000), por ejemplo las oriundas de Santa María compraron todos los lotes ubicados al sur y sudoeste de la aldea. Esta distribución en el espacio da cuenta de cómo ya las dimensiones culturales vinculadas a los patrones migratorios tenían un papel central en las decisiones territoriales del trazado del pueblo. Sumado a esto, otra variable clave en la diagramación era el dominio sobre el espacio productivo: generalmente se trazaban sobre dos calles o una principal y manzanas en forma rectangular, circundadas por calles paralelas y transversales más angostas.

Figura 2. Plano de la Colonia Santa Anita hacia 1930

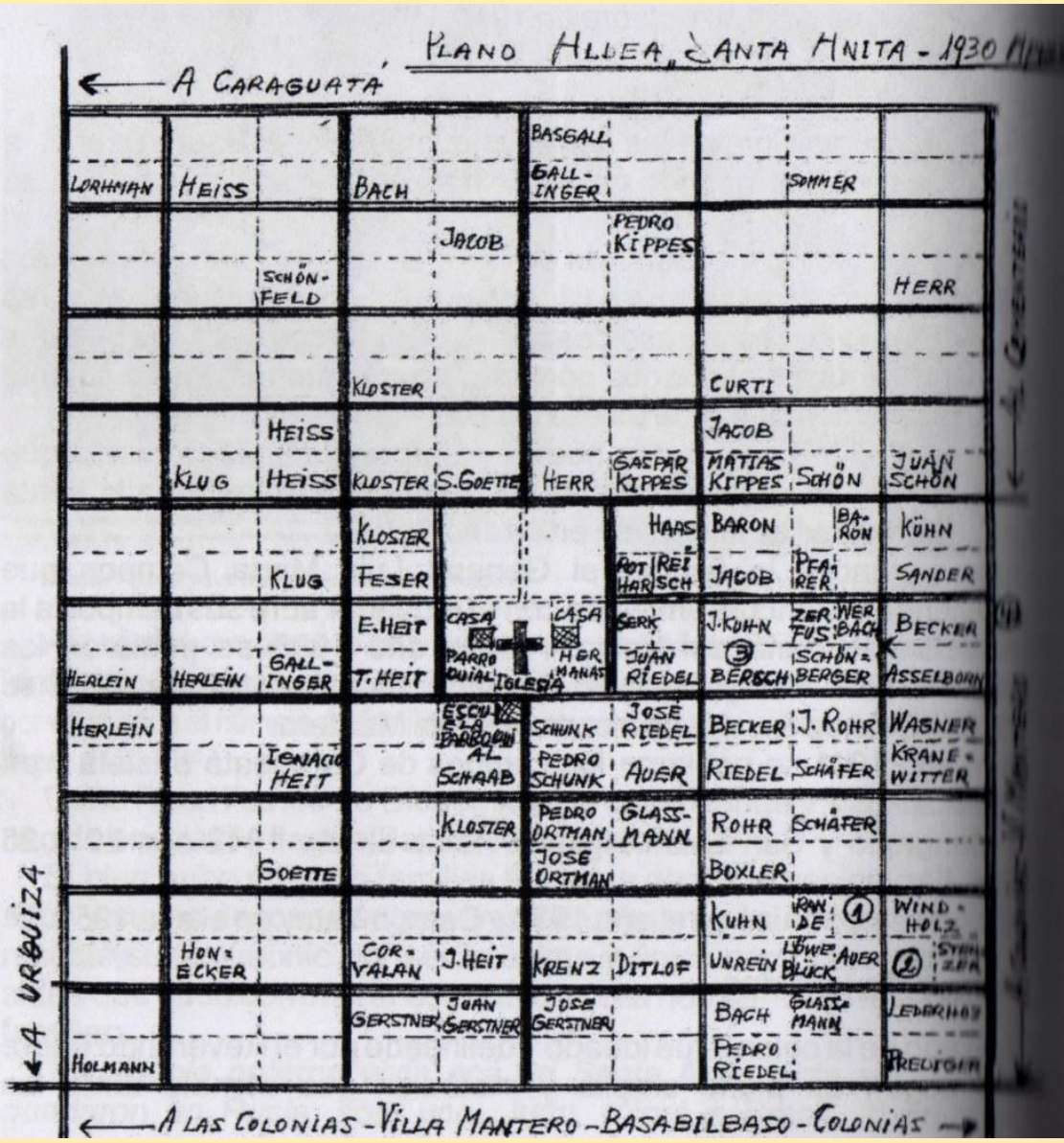

Fuente: Honeker y Jacob, 2000.

Dossiê Turismo: entrecruzamentos de cultura, memória e desenvolvimento 
En el caso de Santa Anita, el diseño fue ideado y delineado por el Padre Becher según un plano amplio y metódico que atendía tanto a las necesidades peculiares del colono como el porvenir expansivo y progresivo de la colonia (ver Figura 2). Su proyección apuntó a la base del modelo que trajeron los alemanes del Volga a la Argentina, donde el componente religioso fue siempre un factor esencial y donde el templo ocupaba un sitio preferencial dentro de las comunidades volguenses. Así, la capilla de culto católico se sitúa en el centro de la aldea sobre la avenida principal y "es, claramente, un espacio de representación" (LEFEBVRE, 1990: 127) al igual que la casa parroquial y la casa de las hermanas. Además, como la aldea reunía a personas de igual origen étnico que estaban bajo las mismas reglamentaciones e idéntica confesión religiosa, se conseguía una mejor utilización de los servicios comunitarios que ofrecía el lugar; "la iglesia siempre fue el refugio de nuestro pueblo, el lugar donde acudían para encontrar paz y descanso" (HONEKER y JACOB, 2000).

En este mismo lote de cuatro hectáreas del centro del radio urbano se planificó la ubicación de la plaza denomina "Plaza del Inmigrante" que fue creada en 1982 por gestión de la Junta de Gobierno de ese entonces. Esta plaza tiene una superficie de $100 \mathrm{~m}^{2}$ y está dividida en dos partes: una zona arbolada y otra con juegos recreativos. Los lotes de los alrededores de la colonia fueron destinados para la actividad agropecuaria, donde también se localizaba el cementerio. Sin embargo, en la actualidad, la expansión urbana de la colonia hizo que el cementerio quede dentro de los límites del poblado. En cuanto a los caminos se planificaron dos vías de acceso: el camino de Villa San Marcial (enripiado en 1960) que empalma con la ruta $\mathrm{N}^{\circ} 12$ y el que lleva a Villa Mantero y comunica con la ruta provincial $\mathrm{N}^{\circ} 39\left(\mathrm{ex} \mathrm{N}^{\circ} 131\right)$.

El emplazamiento urbanístico y la presencia de viviendas con características particulares reflejan, además, una forma específica de organizar el espacio de acuerdo a las pautas culturales de la comunidad que habían traído desde su asentamiento en el Volga. Es por ello que las viviendas de los colonos pioneros en Santa Anita "aparecían como marcas de identidad que daban cuenta de una permanente evocación de las aldeas rusas, reproduciendo el estilo arquitectónico propio de los alemanes del Volga, hecho que también los diferenció de otros grupos, como los daneses del sur de la provincia de Buenos Aires o los galeses de la Patagonia argentina" (FLORES, 2018: 143). Como se observa en la figura $\mathrm{N}^{\circ} 3$, tenían una planta rectangular con techos a dos aguas, que en algunos casos se anexaba una galería. Generalmente el material de la vivienda era el adobe en donde se colocaban alambres en forma horizontal de los parantes de la estructura previamente establecida para entretejer manojos de paja hasta cubrir toda la pared, se construían con ligereza y no contaban con cimientos, se trataba de construcciones precarias. La mayoría eran techadas con zinc y por encima de los techos se 
colocaba paja de trilla con función de aislante para reducir las altas temperaturas que regían en el verano. También, como puede visualizarse en la figura $\mathrm{N}^{\circ} 4$ y 5 , las viviendas de familias más acomodadas económicamente solían utilizar ladrillos unidos con barro para las paredes que luego eran revocadas con el mismo material y una vez que las mismas carecían de humedad las pintaban de blanco con cal, mientras que las aberturas se pintaban de colores fuertes. Además, los frentes de las casas no poseían puertas con el fin de resguardarse en caso de ataques por las tribus nómades, solamente se encontraban las ventanas con un amplio pasillo lateral que era utilizado para la entrada y salida de los carros y en donde se encontraba el acceso principal a la vivienda.

Figura 3. Casa típica de alemanes del Volga en la Colonia Santa

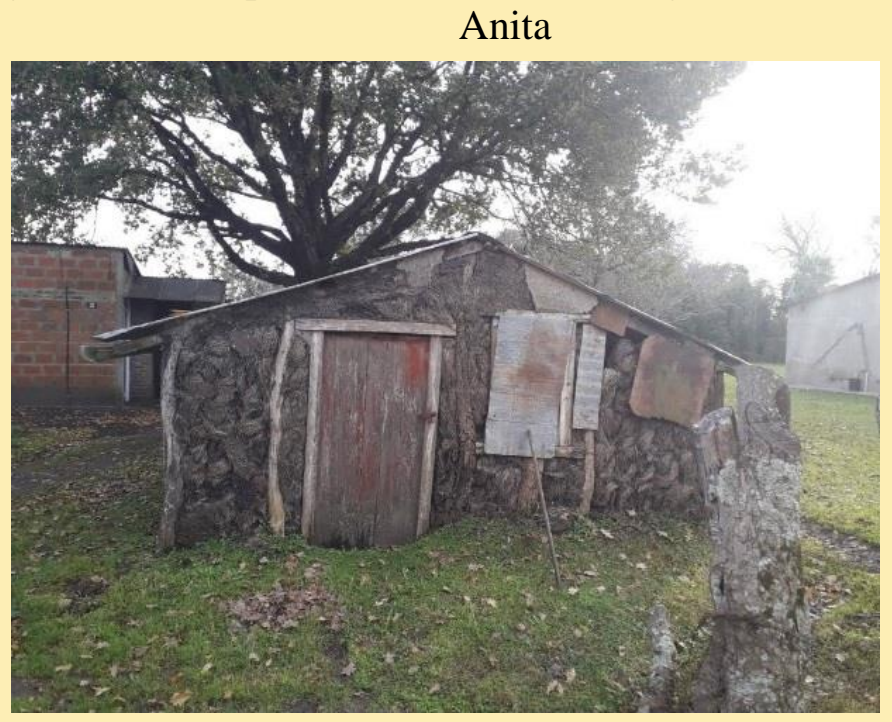

Fuente: Flores y Windholz (2019).

Figura 4. Detalles constructivos de las casas de la Colonia

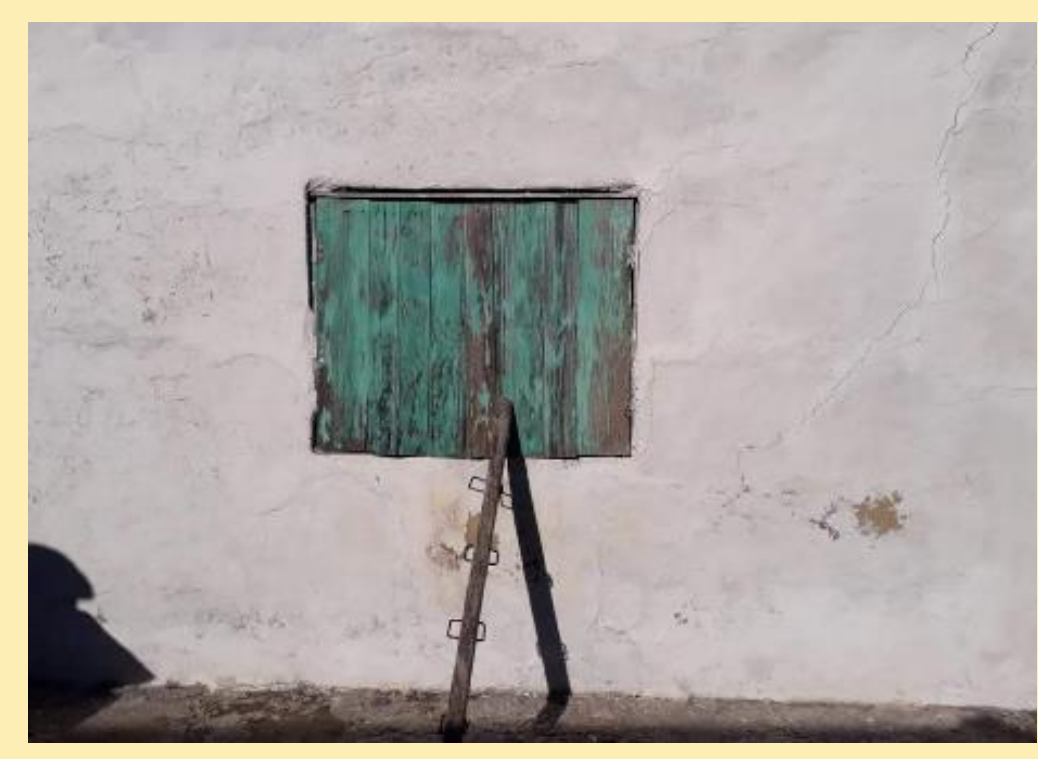

Fuente: Flores y Windholz (2019).

Figura 5. Vivienda de estilo volguense de familias más acomodadas

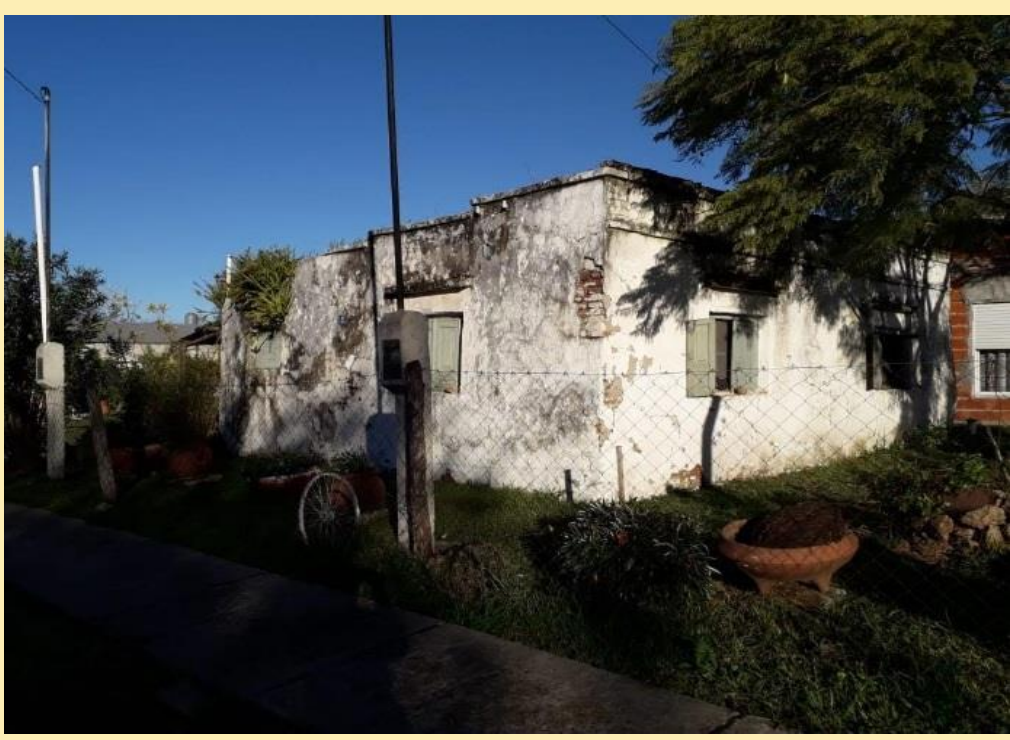

Fuente: Flores y Windholz (2019).

Dossiê Turismo: entrecruzamentos de cultura, memória e desenvolvimento 
Con la llegada de los colonos a estas tierras comenzaron grandes transformaciones espaciales: la tarea de deforestación y corte de pastizales para luego introducir herramientas precarias y de fabricación propia como los arados con los que se abrieron los primeros surcos, las rastras para el proceso de refinamiento de la tierra, el disco para la fragmentación de los campos y el aporcador para la plantación de maíz. Todo ello fue consolidando el perfil agrario de la aglomeración, al igual que muchas otras situadas en las lomadas entrerrianas.

Entre los años 1920 y 1930, los colonos sembraban entre 100 a 200 hectáreas, siempre con más trigo que lino, el maíz solo se plantaba para uso doméstico, consolidando así un paisaje agrario propio de la Colonia. El trigo siempre fue para los Alemanes del Volga la principal producción. En un principio, para extraer el grano se usaban unas máquinas trilladoras a vapor denominadas Die Tresh Maschine (HONEKER y JACOB, 2000), y también se empleaba mucha mano de obra criolla peones golondrinas) quienes trabajaban siempre con el mismo colono. Algo similar ocurría con el maíz, cuando un colono de clase media contrataba a un par de deschaladores encargados de recolectar los choclos maduros. Sin embargo, la aparición de las maquinas trilladoras y sorgo en la década del 1970 fueron haciendo desaparecer las actividades manuales. El cambio tecnológico implicó una transformación en las relaciones de producción y el vínculo con la sociedad criolla.

144
Otra de las actividades que se llevaba a cabo en la colonia fue la arrocera; cada colono sembraba ente 3 a 4 hectáreas (HONEKER y JACOB, 2000) que se recogían con la hoz y se amontonaba sobre las tapias para cárgalo sobre un trineo y llevarlo a tierra firme. Esta actividad brindaba la ventaja de la baja inversión de capital ya que las bombas para extraer agua no requerían grandes gastos de perforación. Pero, la caída de los precios internacionales de los cereales hizo que muchos productores se inclinaran a la ganadería y avicultura las cuales, junto con el trigo, no solo dan cuenta de un recurso económico sino también de una identidad territorial para la colonia convirtiéndose en una forma simbólica espacial (LOBATO CORREA, 2011) ya que, como se observa en la figura $\mathrm{N}^{\circ} 6$, estos símbolos se encuentran expresados en el escudo de la localidad de Santa Anita y constituyen una de las marcas patrimoniales que dan cuenta de la identidad local.

Figura 6: Escudo de la localidad de Santa Anita

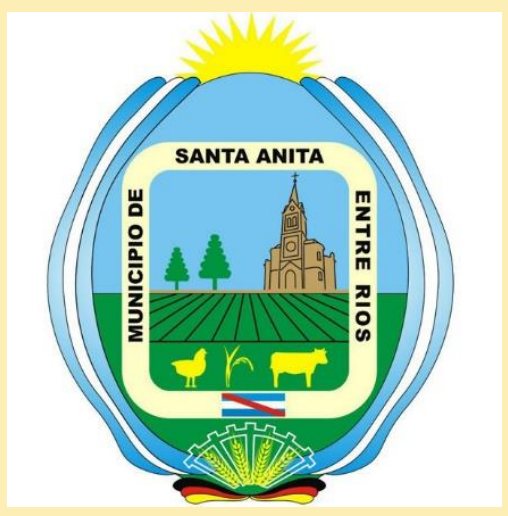

Fuente: http://www.santaanita.gob.ar (última consulta: 17/8/20)

Dossiê Turismo: entrecruzamentos de cultura, memória e desenvolvimento 
Las políticas económicas neoliberales, llevadas a cabo por et Ministro de Economía de la Revolución Argentina, Krieger Vasena, integraban un plan económico con una ley de alquileres que afectaron a los sectores rurales por la falta de protección y la desnacionalización hacia 1966.
Así, en 1950 comenzó el furor de la avicultura que consistía en criar gallinas ponedoras no solo para la producción de huevos para consumo doméstico sino también para venderlos a un acopiador, surgiendo así la figura del "acopiador de huevos" que se encargaba de canjearle a las familias de la colonia mercaderías por huevos para luego revenderlos al mercado de Buenos Aires. Esta actividad fue muy rentable incluso "nuestros colonos vivían básicamente de huevo con una avicultura muy primitiva, muchos mejoraron su calidad de vida llegando en algunos casos a comprar herramientas y maquinarias agrícolas" (HONEKER y JACOB, 2000). Sin embargo, esta actividad quebró debido a la imposibilidad de competencia ante los grupos empresarios de Buenos Aires que monopolizaron el mercado.

A mediados de siglo XX, la colonia fue próspera y su crecimiento registró a 3.500 las familias instaladas en la localidad. Sin embargo con la ley de desalojo de mediados de la década de $1960^{7}$, cientos de familias dejaron la comarca para radicarse en el cercano oeste del área metropolitana y entonces ese número se redujo notablemente.

Para 1968 se instaló la primera firma integradora llamada “Complejo Avícola Santa Anita" y así, esta actividad se convirtió en la principal fuente de trabajo local con un gran éxito productivo: "en 1968 aquellos 13.000 pollos se convertían en 1.000 .000 de pollos en 1998" (HONEKER y JACOB, 2000). Los pollos listos para vender eran llevados vivos para ser comercializados en Buenos Aires y otra parte se faenaba en un pequeño peladero y cámara frigorífica que se había instalado en la localidad.

Para la década del 90 otras actividades fueron apareciendo en la aldea como la cunicultura (crianza de conejos) muy rentable para la fecha y en menor medida la apicultura, pero siempre secundarias a la principal actividad que continuo siendo la avicultura.

A partir del año 2000, cuando se crea el Municipio de Santa Anita, se produjeron grandes trasformaciones en el espacio productivo. Una revolución tecnológica en las que nuevas maquinarias como el sistema de siembra directa, las semillas genéticas y la capacitación y concientización del productor agropecuario llevaron a que los rendimientos de los cultivos aumentaran notablemente. En suma, al aumento de la superficie sembrada se logró que la productividad de la zona se incrementara. En la actualidad Santa Anita cuenta con dos establecimientos agrícolas: por un lado, la infraestructura básica para el almacenado, secado y transporte de arroz, y, por otro lado, un molino arrocero en el que se procesa gran cantidad de arroz de la zona. Con la introducción del pollo híbrido, la avicultura sigue siendo una de las principales actividades productivas de la colonia. Todo esto generó que la aldea alcance los 1380 habitantes (según el CENSO NACIONAL DE POBLACIÓN, HOGARES Y VIVIENDAS 2010), lo que de acuerdo al criterio censal demográfico-morfológico la 
8 https://www.turismoentrerios.com/ https://www.entrerios.tur.ar/ (última consulta: agosto de 2020).

9 Los Caminos del Palacio están conformados por las localidades de Concepción del Uruguay, San Justo, Caseros, Herrera, Mantero, Basavilbaso, Pronunciamiento, San Anita y Rosario del Tala, entre otros. población de Santa Anita es rural-aglomerada ya que no supera los 2000 habitantes.

Las transformaciones en los imaginarios sociales sobre lo rural, el tipo de prácticas económicas y los impactos que estas producen en el ambiente y la sociedad alteraron los esquemas convencionales de la organización del territorio productivo. Por un lado, la producción avícola, tradicional en la zona fue generando reclamos por fuertes olores y presencia de moscas en la zona residencial; la producción del molino arrocero también comenzó a generar inconvenientes por la dispersión de partículas en el aire, y la producción agrícola sobre la base del uso de agroquímicos, cada vez más presente, ocasionó conflictos por las fumigaciones con pesticidas y herbicidas en las proximidades de las zonas residenciales, especialmente en escuelas.

Por otro lado, el incipiente posicionamiento de Santa Anita como destino turístico y residencial se desencadena, en principio, por el retorno de aquellos pobladores que décadas atrás, excluidos del proceso de intensificación productiva, migraron a centros urbanos en busca de trabajo. Este repoblamiento es selectivo y altera los imaginarios sobre la ruralidad (FLORES, WINDHOLZ, 2019). Además, es promovido por el Estado municipal que busca capitalizar su activo simbólico y paisajístico con la puesta en valor de ese paisaje neorrural a través de distintos caminos: el impulso de nuevos atractivos (naturales y culturales); la puesta en valor del patrimonio histórico, el fomento para aumentar las "camas disponibles" en la localidad y la reserva de áreas urbanizables o de urbanización diferida.

\section{4 - Turismo y patrimonio en Santa Anita:}

\section{realidades y potencialidades}

La provincia de Entre Ríos, unidad administrativa en la que se emplaza la localidad de Santa Anita es una de las visitadas del país, sobre todo por turistas provenientes de las provincias de Buenos Aires y Santa Fe que, favorecidos por la cercanía y las vías de acceso, optan por gran parte de las localidades turísticas entrerrianas. Las rutas nacionales $\mathrm{N}^{\circ} 12$ y la $\mathrm{N}^{\circ} 14$ (paralela al río Uruguay) constituyen las arterias centrales que conectan el flujo de visitantes con los principales centros urbanos del litoral y centro del país. Justamente, cuando en 2005 el gobierno nacional lanzó el «Plan Federal Estratégico de Turismo Sustentable 2016 (PFETS)» se definieron estrategias y marcos particulares de acción para cada una de las provincias argentinas, delimitando áreas prioritarias regionalmente. Para el caso de Entre Ríos, el PFETS “reconoce al Corredor Turístico del Río Uruguay como prioritario, y como potencial al del Río Paraná (inferior); como áreas con vocación turística para desarrollar a los circuitos productivos de las colonias entrerrianas (centro-sur); como puertas actuales a Paraná-Santa Fe, Rosario, Concordia, Colón y Gualeguaychú, a su vez que estas tres 
10 Entrevista realizada a Lucas Schmidt, Secretario de Cultura, Turismo y Comunicación Ciudadana del Municipio de Santa Anita, agosto de 2020 .

${ }^{11}$ Ordenanza Municipal No0105/15, "Organigrama Municipal" (18/02/2016).

${ }^{12}$ Ordenanza Municipal No0105/15, "Organigrama Municipal" (18/02/2016).

13 Por ejemplo, el Hospedaje Cabañas "La Rústica" se presenta como: "un lugar especial para escapar de la rutina y tener un merecido descanso; el Hospedaje "Las Violetas" refiere a la tranquilidad y la calma del lugar que te "ayuda a que te sientas en tu casa"; y el Hospedaje "Los Lolos" se presenta en sintonía con los imaginarios de paz, serenidad y naturaleza.

${ }^{14}$ Diario Página 12, 17 de abril de 2016 -Suplemento TurismoParalelo Turístico, 2020; Región Litoral, Portal del Litoral Argentino, 2020 (últimas consultas agosto de 2020). últimas son consideradas como circuitos transfronterizos actuales y finalmente como travesías incluye a la ruta nacional 127 y provinciales 39 y 11, mientras que como travesía destacable hacia el mediano y largo plazo se encuentra la ruta nacional 18" (WALLINGRE, 2018:20).

En términos de atractivos, modalidades y ofertas, la provincia profesa amplia diversidad: playas, actividades deportivas, naturaleza, historia, termas, fiestas populares y cultura son los tópicos que aparecen con mayor presencia en las páginas oficiales y emprendedores turísticos. ${ }^{8}$ El Corredor del río Uruguay constituye la región más dinámica con respecto al turismo e incluye destinos claves como: Concordia, San José, Gualeguaychú, Federación, Villa Paranacito, Colón, Santa Ana, Concepción del Uruguay, Villa Elisa, Chajarí, Puerto Yeruá, San Salvador, Pueblo Belgrano, Ubajay, Villa del Rosario, San Salvador, Liebig o Santa Anita, objeto de indagación del presente trabajo.

Asimismo, en sintonía con los planes nacionales, la provincia y algunas de las principales ciudades y localidades entrerrianas llevaron adelante políticas públicas vinculadas el ordenamiento y la promoción turística local y regional, como el caso de la construcción de micro regiones turísticas articuladas por las principales localidades turísticas, rutas y accesos. "Fueron creadas once, separadas entre las pertenecientes a la Costa del Río Uruguay y del Río Paraná. Entre las primeras se encuentran los Caminos de los
Azahares, Rural, Tierras del Palmar, Caminos del Palacio y Colonias Judías. Entre las segundas, la Ruta del Dorado, Paseo de las Colonias, Capital, Aldeas Alemanas, Lomadas Entrerrianas y Pueblos del Sur" (WALLINGRE, 2008: 23). Esta iniciativa surge en el marco del Plan Estratégico de Desarrollo Turístico Sustentable de Entre Ríos puesto en marcha a partir del 2007, y el funcionamiento de estas microrregiones tuvieron resultados dispares e inclusive poco sostenidos en el tiempo.

Por su emplazamiento periférico entre las rutas 12, 14, 39 y 130, la localidad de Santa Anita fue sumada a los Caminos del Palacio 9 a pesar de no estar situada sobre la ruta 39 que articulaba el camino turístico; sin embargo hacia 2014 el proyecto se cayó y no pudo seguir avanzando a nivel interdepartamental. Uno de los factores que más ha complejizado el sumarse a algunas estructuras turísticas tiene que ver con el acceso a la aldea. De hecho, el Secretario de Cultura, Turismo y Comunicación Ciudadana del Municipio de Santa Anita menciona que: "recién empezamos a apostar al turismo en los últimos años a partir de que tuvimos un acceso asfaltado; antes eso era imposible"10. Así, la Secretaría local logró sumar a la Colonia a uno de los Corredores turísticos promovidos desde la provincia: el Corredor del Gualeguay, subsidiario de una de las rutas turísticas más importantes de todo Entre Ríos: el Corredor del Uruguay (área centro), que contiene a 
algunos de los nodos turísticos más visitados como: Gualeguaychú, Colón, San José, el Parque Nacional El Palmar, entre otras.

Esta medida impulsó a la práctica turística que se sumó como una actividad incipiente y dinamizadora de economía de la Colonia. En el Organigrama Municipal, las políticas patrimoniales y turísticas se coordinan desde la Secretaría de Turismo, Cultura y Comunicación Ciudadana. La estructura adoptada desde el Municipio establece un esquema dual que prioriza las cuestiones patrimoniales al área de Cultura, mientras que las turísticas al de turismo, y si bien ambas áreas funcionan conjuntamente bajo la esfera de la misma Secretaría, esto da cuenta de las formas en las que el estado municipal percibe y concibe ambas políticas públicas. En este sentido, la Ordenanza $\mathrm{N}^{\circ} 0105 / 15$ que establece el "Organigrama Municipal”, adjudica al área de cultura, entre otras funciones: “c. La preservación y conservación del patrimonio natural y del patrimonio cultural material e inmaterial, sus elementos tangibles e intangibles, como centro de la preservación de nuestra identidad y d. establecer pautas de conservación del patrimonio histórico local, organizar las recordaciones de la ciudad y fiestas patrias. Actuando como responsable de ceremonial, para todos los eventos oficiales del Municipio"11. La misma reglamentación otorga al área de Turismo: “a. Planificar el desarrollo y aprovechamiento integral turístico del ejido municipal; b. Fomentar, promover y difundir la actividad turística como industria no contaminante

Dossiê Turismo: entrecruzamentos de cultura, memória e desenvolvimento mediante las planificaciones, promociones, acuerdos, adhesiones, gestiones y cualquier otra medida concurrente; c. Proyectar e implementar programas tendientes a conservar, incrementar, mejorar y difundir el patrimonio turístico de Santa Anita; d. Será directamente responsable del acondicionamiento y pleno funcionamiento del Parque y Balneario Municipal y de la organización y supervisión del Museo Municipal"12.

Las bases de la actividad turística en la actualidad se sitúan en torno a la consolidación de dos tipos de atractivos que se ponen en valor: por un lado, el entorno natural que recupera el paisaje entrerriano con la presencia de lomadas, lagunas y las actividades deportivas relacionadas a este entorno, específicamente la pesca deportiva y el camping. Por otro lado, los atractivos culturales vinculados a la herencia patrimonial (material e inmaterial) de los alemanes del Volga y los imaginarios turísticos (HIERNAUX, 2002) de pueblo "tranquilo", "pulcro", “seguro", “pujante”, “con calles silenciosas", que se construyen tanto desde el estado municipal y provincial, como desde los pocos operadores turísticos ${ }^{13}$ y la prensa que aflora en la idea de comarca bucólica y detenida en el tiempo. ${ }^{14}$

En este sentido, los atractivos seleccionados intentan reforzar, por un lado, ofertas similares a las que cuentan gran parte de otras localidades cercanas (y no tanto) del Corredor turístico, como la puesta en valor del paisaje natural de las lomadas entrerrianas y las lagunas con todas las actividades de ocio y deportivas que se 
consumen en estos sitios, tanto públicos como privados apoyados en imaginarios que privilegian "la naturaleza", "la tranquilidad" y "el entorno paisajístico”. En esta dirección se destaca:

- El Balneario Camping Municipal: que es un predio de 8 hectáreas atravesado por un arroyo, en el que se construyó una playa artificial que constituye "el" atractivo más promocionado por el Municipio y que desarrollaremos más adelante. El balneario si bien es municipal tiene un costo de ingreso y sus actividades se concentran en la temporada estival. La web de la provincia menciona que: "Santa Anita tiene una muy buena infraestructura para la práctica de deportes, un gran polideportivo municipal y a su vez su único Club el Centro Deportivo “el Porvenir” cuenta con excelentes instalaciones. Está en construcción un Camping Municipal con pileta e infraestructura para campamentos." 15

- Proyecto de Piscicultura Municipal de Santa Anita: en el mismo predio donde se encuentra el Balneario Municipal está ubicado el proyecto de piscicultura; son lagunas artificiales para la pesca deportiva donde funciona un sistema de "pesque y pague" abonando por kilo de lo pescado. Además, se brinda la posibilidad de alquilar el equipo de pesca completo, el servicio de faena y guardado y consumir o no lo que se pesque. Cuenta con diversidad de especies tales como: pacú, dorado, surubí, boga y tilapia, entre otras. También hay una Huerta Orgánica que ofrece sus productos. Todo este tipo de actividades recreativas son controladas por parte del estado municipal.

- Pileta y Camping “En Mein Andenken" (Mi Recuerdo): Este complejo privado cuenta con dos piletas, parrillas, hornos de barro, un quincho, canchas de futbol y vóley. Además, promueven un paseo en carros y sulkys a $7 \mathrm{~km}$ de la localidad para demostrar el desplazamiento de los primeros colonos y cuenta con un sector donde se exhiben herramientas y carros con los que trabajaban los colonos. Combina las actividades recreativas y el paisaje natural con el patrimonio cultural del legado inmigratorio de los alemanes.

Por otro lado, complementarios a estos atractivos aparece el consumo del patrimonio como activador de la práctica turística. Sobre todo considerando que: "la puesta en valor y uso del patrimonio a través del turismo es pensada como vía para lograr el desarrollo de determinadas áreas o localidades donde este patrimonio se encuentra y como alternativa a las crisis de las economías regionales y locales" (TRONCOSO y ALMIRÓN, 2005). En este sentido, el Municipio opera activamente en la recuperación y puesta en valor de una política patrimonial vinculada al legado de los alemanes del Volga. El Secretario de Cultura, Turismo y Comunicación Ciudadana de Santa Anita mencionaba que:

en la política patrimonial se trata de llegar a un acuerdo con los privados, no expropiar y tratar de hacerles comprender el valor turístico y cultural que tiene su propiedad [...] en estos acuerdos se ha puesto en valor una casa de estilo del Volga de 
16 Entrevista realizada a Lucas Schmidt, Secretario de Cultura, Turismo y Comunicación Ciudadana del Municipio de Santa Anita, agosto de 2020.
1920, donde el año pasado el Municipio se encargó de la restauración exterior; al principio la familia no quería, pero luego se logró hacer un convenio para la restauración exterior [...] el próximo paso es entrar a la casa para hacer una restauración interior y que se transforme en una casa museo ${ }^{16}$.

Así se observa como el Estado municipal opera como principal activador de la patrimonialización, siendo la voz autorizada para seleccionar y certificar el patrimonio "legitimo" (SMITH 2006; 2011). Actualmente, se está proyectando poner en valor otra propiedad del mismo estilo volguense que tiene la particularidad de haber sido el hogar del único Obispo que tuvo Santa Anita. Esta condición, funciona a priori como característica válida de entrar en el catálogo patrimonial y fortalecer el discurso patrimonial autorizado (SMITH, 2011); discurso que se apoya en la identidad del lugar enraizada en la Colonia de alemanes del Volga de cepa católica, y a que la vez la diferencia de otras colonias de los alrededores de origen protestante. Después de todo, "los elementos seleccionados son acompañados por discursos que los justifican y legitiman como tal" (PRATS, 2006: 103) y aportan contenido a la construcción del lugar.

Para Laurejane Smith, el "discurso autorizado" se construye a través de valores de la elite occidental dominante cuya función es naturalizar una serie de supuestos sobre su significado (SMITH, 2011). Al igual que en otras experiencias turísticas de sitios donde la migración tuvo un peso fundamental, en Santa Anita se fue estructurando "una sociedad local donde la presencia de referentes identitarios propios de estos primeros migrantes se mantiene muy presente; el Museo Histórico local es una de las expresiones de esto" (BERTONCELLO, 2008: 191). Así, otro conjunto de atractivos que responden a la puesta en valor del patrimonio autorizado (material e inmaterial) forman parte de la oferta de la localidad:

- Museo histórico: inaugurado en 2016, tiene la particularidad de conservar el patrimonio material de los "antepasados" y "pioneros". Se trabaja con visitas personalizas o independientemente. Poseen un archivo con documentación de acceso libre y gratuito con materiales audiovisuales que incluye programas específicos con contenido "volguense" que mantienen relatos, historias de vida e historias de la comunidad. Es de alguna manera la institución que "resguarda" el patrimonio material e inmaterial de la comunidad.

En estas líneas, una de las actividades que se traccionan desde las Secretaria Municipal es el evento "La Noche del Museo" que se lleva a cabo en sintonía con un programa estatal "Verano en Santa Anita" y una política a nivel provincial. Esta actividad se llevó en el Museo Histórico que fue ambientado (con luces y escenografía de "época") recreando la vida de los colonos pioneros alemanes del Volga. Para la segunda edición que se realizaría en 2020 se está pensando en sumar las actividades en el exterior (trilladoras, por ejemplo) con danzas "típicas" y comidas de los inmigrantes. Este dispositivo cultural fue pensado "exclusivamente 
17 Entrevista realizada a Lucas Schmidt, Secretario de Cultura, Turismo y Comunicación Ciudadana del Municipio de Santa Anita, agosto de 2020. para el turista $[. .$.$] y aunque los vecinos se suman, se piensa como$ algo turístico" 17 fortaleciendo no solamente el patrimonio autorizado, sino también la identidad del lugar de una aldea inmigratoria volguense.

Figura 7: Afiche de promoción del programa "Verano en Santa Anita"

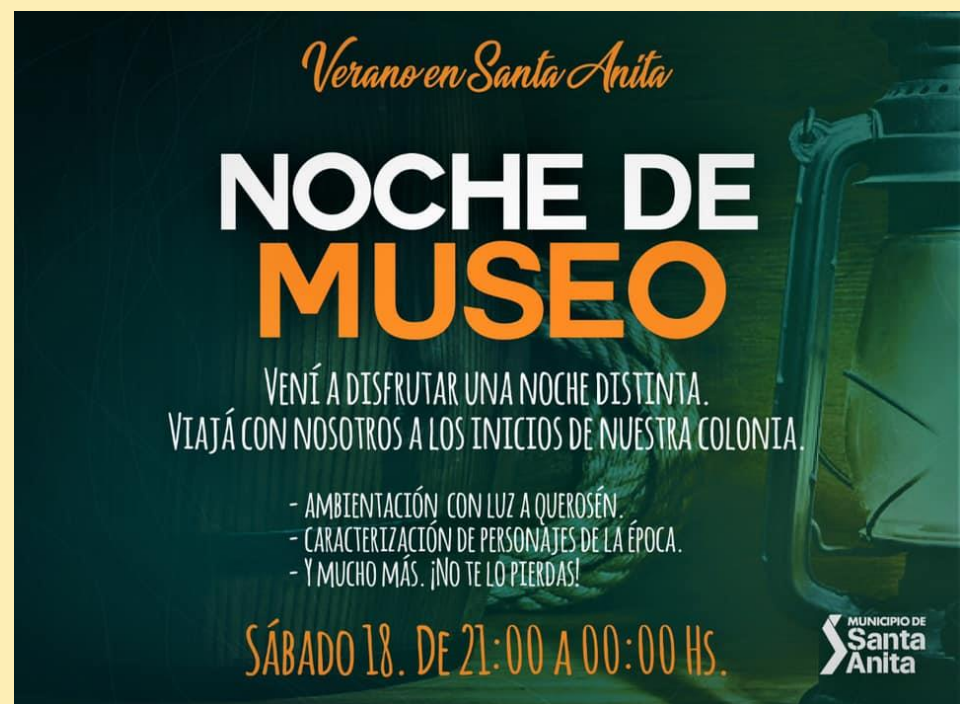

Fuente: http://www.santaanita.gob.ar/ (última consulta agosto de 2020).

- Plaza del Inmigrante: en el catálogo patrimonial local aparece la plaza como otro de los atractivos. Como se mencionó anteriormente, el predio que ocupa actualmente la plaza estaba incluido en el lote de 4 hectáreas del centro del radio urbano que correspondía a la iglesia Parroquial. Su creación data de 1982 por gestión de la Junta de Gobierno de ese entonces y lleva el nombre de Plaza del Inmigrante en memoria de todos aquellos inmigrantes de Volga que trabajaron las tierras de Santa Anita. Además, es promocionada no solo como un espacio público con variados juegos, sino que también es aquel punto de encuentro donde se realizan festivales musicales, muestras de artesanos locales, ferias de comidas típicas, etc.

- Iglesia: por ser una aldea de raíz católica, la Iglesia ocupó y ocupa un lugar central en la trama urbana y como espacio de representación de toda la comunidad. El edificio comenzó a construirse en 1910 en el centro de la colonia a 10 metros de la capilla primitiva y fue inaugurada provisoriamente para la navidad de 1913 . Posee $46 \mathrm{~m}$ de largo y $24 \mathrm{~m}$ de ancho y las tres naves llegan a $18 \mathrm{~m}$, mientras que su torre alcanza los $40 \mathrm{~m}$ de altura. Fue diseñada y construida con una mezcla entre los estilos gótico por sus ventanas en medio punto con vitreaux artísticos de figuras religiosas y su torre como aguja de piedra (que luego paso a ser del estilo Normando) y romántico por sus puertas con numerosas bóvedas y sus paredes con ladrillo sin revocar. Cuenta con 27 vitrales traídos de Alemania, un Altar Mayor y Comulgatorio de mármol de Carrara, entre otros elementos. Todos estos elementos de la arquitectura se enaltecen como muestra del valor patrimonial que la comunidad preserva. 
- Casa volguense donde falleció el Reverendo Padre Enrique Becher: este atractivo está en proceso de patrimonialización en la actualidad ya que se trata de una vivienda que actualmente está ocupada por sus propietarios. La Municipalidad inició gestiones con los actuales dueños para empezar a poner en valor el inmueble como patrimonio, pero hasta el momento solo se logró que se les permitirá restaurar y la habitación donde falleció el líder fundador. Se intenta en una segunda etapa patrimonializar toda la casa y ponerla en valor como atractivo cultural de la localidad. Por el momento, junto con el museo, en fechas específicas se puede acceder a conocer elementos propios del fundador como el cáliz, rosarios, entre otros, pero no tiene apertura permanente.

- Fiestas comunitarias: dos son las festividades más importantes de la localidad y que operan como dispositivos identitarios:

Por un lado, desde el 8 de diciembre de 1998 todos los años se realiza la "Fiesta Nacional de la trilla" que se desarrolla durante tres días funcionando como un vínculo que une el pasado agrícola de la colonia con el presente turístico de la aldea, en donde se muestra al público como trabajaban la tierra los primeros colonos con máquinas agrícolas del año 1919 hasta 1945. Es el evento más reconocido y valorado de la comunidad en tanto constituye un componente clave que refuerza la identidad del lugar como colonia agrícola de inmigrantes. Además ofrecen una feria gastronómica con platos típicos de la región del Volga, cerveza artesanal, distintas propuestas musicales y bailes típicos. Todos estos dispositivos ponen en valor y materializan un discurso patrimonial legítimo que se condensa en la fiesta y sus distintos componentes.

Por otro lado, todos los 26 de julio se festeja la "Fiesta de Santa Ana”, que nació con la fundación del pueblo. En la jerga popular se la conoce con el nombre de "Kerp", vocablo derivado de la palabra Kirchewein que significa bendición de la iglesia. Durante esta fiesta religiosa, la plaza es invadida por banderas argentinas y alemanas, y la estatua de Santa Ana preparada sobre andas es movilizada recorriendo las calles de la aldea luego de la misa, por madres de llamadas "Ana" (en la medida de lo posible). Al día siguiente de la Fiesta Patronal, se procede a la visita del cementerio para orar por los difuntos y también se promueven almuerzos populares. Al igual que en el caso anterior, esta fiesta además de legitimar el patrimonio volguense, refuerza otro componente central del colectivo migratorio: su religión católica.

La construcción de este tipo de atractivos entonces, recupera la historia local y su identidad de lugar vinculada con la inmigración ruso-alemana, la existencia de instituciones que la expresan, sus costumbres, las marcas en el paisaje, sus festividades, entre otras. La promoción de esta oferta perfila un turismo cultural que se apoya, en gran medida, en la valorización del patrimonio como atractivo turístico (BERTONCELLO, 2008). 
18 Entrevista realizada a Lucas Schmidt, Secretario de Cultura, Turismo y Comunicación Ciudadana del Municipio de Santa Anita, agosto de 2020.

19 www.paraleloturistico.com.ar/playaartificial-en-santa-anita (última consulta: agosto de 2020).

${ }^{20}$ Región Litoral, Portal del Litoral Argentino (última consulta: agosto de 2020).
Finalmente, merece mención aparte una atractividad nueva que posee la localidad y que se exterioriza desde el estado municipal y desde los imaginarios turísticos locales como el elemento diferencial de la oferta regional. Se trata de una playa artificial que fue construida por el Estado dentro del predio del Balneario Municipal, y que se identifica desde el discurso autorizado como lo "único", lo "distinto" y lo "particular". El propio Secretario de Cultura, Turismo y Comunicación enfatizaba esta idea: "el balneario y la playa artificial es nuestro 'caballito de batalla'. Por la playa artificial han venido de toda la provincia a visitarnos y a ver esto, porque no hay en otro lugar una playa artificial [...] y esto es lo que más movió y lo que más hizo que crezca el turismo en la localidad"18

Desde los medios se refuerzan estos imaginarios turísticos que consolidad al lugar: se trata de una localidad con "una ingeniosa propuesta que permite que el pueblo goce de un espacio de recreación para turistas y lugareños"19; "es un predio de 8 hectáreas atravesado por un arroyo, se construyó un playa artificial alimentada con agua de pozo profundo, se plantaron más de 600 árboles de distintas especies, se construyeron asadores, sanitarios, comedor y una proveeduría, cuenta con cancha de fútbol y beach vóley”. ${ }^{20}$

Este atractivo se inserta en el mapa regional de ofertas turísticas como la novedad; la distinción que posiciona a la localidad de Santa Anita como un potencial polo turístico con una oferta diferencial a todo el Circuito del Corredor (que posee actividades deportivas, lagunas, turismo termal, turismo rural, turismo cultural, entre otros).

En esa dirección es que el Municipio de Santa Anita está trabajando con otras localidades como la de Villa Elisa (distante a 60 $\mathrm{km}$. aproximadamente), cuya actividad turística no solamente es mayor sino que se encuentra mucho más consolidada. Así, se están realizando convenios para lograr que los turistas que pernoctan en esta localidad pueden ingresar gratis a la playa artificial, y que a su vez los visitantes del Balneario de Santa Anita tengan descuentos en las termas de Villa Elisa. Esta estrategia a nivel regional y del propio Corredor Turístico da cuenta de la potencialidad que tiene el turismo como dinamizador de la actividad económica de la aldea.

Así, el lugar siempre es resultado de la convergencia de proyectos, prácticas y actores, que en constante tensión, dinámica y negociación operan constantemente en la producción de la espacialidad y legitiman formas, imaginarios y materialidades que se le van asignando.

\section{5 - Conclusiones}

Los orígenes de la Colonia de Santa Anita están íntimamente ligados a la inmigración de alemanes del Volga que, al igual que en otros espacios rurales de la provincia y del país, se organizaron bajo la lógica espacial de una colonia agrícola. 
Ese pasado directamente vinculado a la inmigración y su presente con cambios en las estructuras productivas, sociales y culturales muestra un horizonte novedoso en la organización espacial y social de la Colonia.

Como hemos advertido el nuevo siglo XXI encuentra a la localidad de Santa Anita inserta en nuevos usos del espacio rural que denotan una tercerización de las actividades productivas donde el turismo emerge con alto nivel de potencialidad. La emergencia y consolidación de atractivos naturales con distinción al del resto de las localidades turísticas vecinas (como el balneario con playa artificial) y la puesta en valor del patrimonio legítimo de los alemanes del Volga (tanto material como inmaterial) perfilan la mezcla de un turismo amplio que se apoya en la resignificación del pasado consumido bajo la forma de patrimonio cultural. En este sentido y siguiendo con Troncoso y Almirón (2005) es posible "pensar el turismo como una práctica que resignifica el patrimonio a partir de procesos sociales de construcción de atractividad turística, esto es, de valorizarlo como atractivo turístico de un lugar. Por lo cual, también, es posible reconocer que a través de la práctica turística el patrimonio entra al mercado para ser consumido pues dicha práctica lo convierte en una mercancía.” (p. 68).

Así, el estado municipal pregona un uso turístico del patrimonio que, por supuesto, no está exento de disputas y tensiones (como la cuestión de la recuperación y mantenimiento de las viviendas volguenses que están en manos de propietarios privados).

A modo de cierre podemos decir que la localidad se posiciona con un perfil de turista familiar cuyas actividades se concentran en torno al periodo estival (el Balneario, la playa, la pesca deportiva, el camping municipal, el conjunto de eventos que la Municipalidad promociona al respecto del patrimonio de los alemanes, incluidas las fiestas populares). El desafío que traza la actual gestión municipal es ampliar este rango a las propuestas invernales sumando nuevos "tipos" de visitantes, como el caso del turismo estudiantil o el turismo de jubilados, que frecuentemente se alojan en las localidades termales cercanas.

\section{Referencias}

ALMIRÓN, Analía. "Turismo y espacio: aportes para otra geografía del turismo.” En: Geousp Espaço e Tempo, n.16, 2004, p.166-180.

BENDIX, Regina. "Heritge Between Economy and Politics: An Assessment from the Perspective of Cultural Anthropology"'. En: SMITH, Laurajane y AKAGAWA, Natsuko (Eds.), Intangible Heritage. Londres, Routledge, 2009, p. 253-269.

BERTONCELLO, Rodolfo. "Turismo y territorio: otras prácticas, otras miradas." En: Aportes y Transferencias, v. 6, n. 2, 2002, p. 29 50. 
BERTONCELLO, Rodolfo. "Turismo, cultura y patrimonio. La ciudad - colonia San José (Entre Ríos)”. En: BERTONCELLO Rodolfo (Comp.), Turismo y geografía. Lugares y patrimonio natural-cultural de la Argentina. Ciccus: Buenos Aires, 2008.

BERTONCELLO, Rodolfo, Hortensia CASTRO, y Perla ZUSMAN "Turismo y patrimonio: una relación puesta en cuestión." En: BERTONCELlO, Rodolfo y FANI CARLOS, Ana (Comps.). Procesos territoriales en Argentina y Brasil. Buenos Aires: Instituto de Geografía, 2003, p. 277-291.

CRESSWELL, Tim. Place: a short introduction. Oxford, Blackwell, 2007.

HIERNAUX-NICOLAS, D. "Turismo e imaginarios". En HIERNAUX-NICOLAS, D. y CORDERO, Allen (Eds.), Cuaderno de ciencias sociales 123, Imaginarios sociales y turismo sostenible. Facultad Latinoamericana de Ciencias Sociales (FLACSO), 2002, p. 7-36.

LOBATO CORRÊA, R. "Las formas simbólicas espaciales y la política". En: ZUSMAN, P.; HAESBAERT, R.; CASTRO, H. y ADAMO, S. (eds.), Geografías Culturales: aproximaciones, intersecciones y desafíos. Buenos Aires. Ed. de la Fac. de Filosofía y Letras de la UBA. 2011.
FLORES, Fabián, La colina de la esperanza. Espacialidad y religiosidad en los orígenes de la aldea adventista de Puiggari, Buenos Aires: Ilustre, 2018.

FLORES, Fabián y CÁCERES Carlos. "Heterodoxias turísticas. Lo exótico y misterioso como atractivo en los valles Calchaquíes de Salta”. POSICIÓN, v. 1, n.1, 2019, p. 1-25.

FLORES, Fabián y WINDHOLZ, Darío. “La producción cultural del espacio rural en una colonia entrerriana. Usos, discursos, actores y prácticas". Red Sociales, Revista del Departamento de Ciencias Sociales, v. 6, n. 3, 2019, p.128-144.

HONEKER, O. y JACOB, M. Santa Anita: nuestras raíces, una historia apasionante..., 2000, Santa Anita. Argentina: Edición de las autoras.

LEFEBVRE, H. The Production of Space. Cambridge: Blackwell, 1990 (original 1974).

PÉREZ WINTER, Cecilia. "La gestión turístico-patrimonial de los centros históricos. Dos "pueblos" de la pampa bonaerense (Argentina)". En: NIGLIO, Olimpia, Ciudades históricas entre Oriente y Occidente. Ermes Ediciones, 2015.

PÉREZ WINTER, Cecilia. "Del turismo "cultural" al "rural": un caso de la Pampa bonaerense (Argentina)". Cuadernos de Geografía, Revista Colombiana de Geografía, v. 26, n. 2, 2017, p. 261-278. 


\section{Fabián Claudio Flores}

Darío Windholz

PRATS, Llorenç. "La mercantilización del patrimonio: entre la economía turística y las representaciones identitarias", Boletín del Instituto Andaluz del Patrimonio Histórico, n. 58, 2006, p.72-80.

SANTANA TALAVERA. "Mirar y leer: autenticad y patrimonio cultural para el consumo turístico". $6^{\circ}$ Encontro Nacional de Turismo com base local, Campo Grande, 2002, p.1-22.

SMITH, Laurajane. Uses of Heritage. Londres, Routledge, 2006.

SMITH, Laurejane. “"El espejo patrimonial'. ¿Ilusión narcisista o reflexiones múltiples?”. Antípoda. Revista de Antropología y Arqueología, n. 12, 2011, p. 39-63.

TOSELLI, Claudia. "Algunas reflexiones sobre el turismo cultural". PASOS. Revista de Turismo y Patrimonio Cultural, v. 4, n. 2, 2006, p. 175-182.

TRONCOSO, Claudia y ALMIRÓN, Analía. "Turismo y patrimonio: hacia una relectura de las relaciones". Aportes $y$ Transferencias, v. 9, n. 1, 2005, p. 56-74.

WALLINGRE, N. "Evolución del desarrollo del turismo en la provincia de Entre Ríos, Argentina". Tiempos de gestión, v. 5, n. 5, 2018, p.13-34. 